\title{
Exploring Existential Coping Resources: The Perspective of Koreans with Cancer
}

\author{
Fereshteh Ahmadi ${ }^{1}$ Jisung Park ${ }^{2}$ Kyung Mee Kim³ \\ Nader Ahmadi ${ }^{1}$
}

Published online: 16 March 2016

(C) Springer Science+Business Media New York 2016

\begin{abstract}
The present study aimed to explore the use of meaning-making coping (existential, spiritual, and religious coping) among cancer patients in Korea and to investigate the impact of culture on their choice of coping methods. Thirty-three participants with various kinds of cancer were interviewed. Four different kinds of coping resources emerged from analyses of the interview transcripts: (1) belief in the healing power of nature; (2) mind-body connection; (3) relying on transcendent power; and (4) finding oneself in relationships with others. The findings of this study suggest the importance of investigating cultural context when exploring the use of the meaning-making coping strategies in different countries.
\end{abstract}

Keywords Coping resources - Meaning-making coping - Koreans with cancer · Existential coping

\section{Introduction}

During recent decades, attention has been paid to the importance of existential questions in health. While some studies have focused on the role of religiosity and spirituality in treatment of disease (Cobb et al. 2012; Koenig et al. 2012; Padela and Curlin 2012; Phelps et al. 2009; Tarakeshwar et al. 2006), others have disputed the actual importance and effectiveness of such coping methods for patients with serious illnesses (Poole and Higgo

Jisung Park

jisungp@hotmail.com

1 Department of Social Work and Psychology, Faculty of Health and Occupational Studies, University of Gävle, Gävle, Sweden

2 Retirement Research Center at Samsung Life Insurance, 7th Flr., 55 Sejong-Daero, Jung-Gu, Seoul 100-716, Korea

3 Department of Social Welfare, Soongsil University, Seoul, Korea 
2010; Powell et al. 2003; Sloan 2006; Sloan et al. 2001). According to several researchers, there is no clear evidence to support the notion that "spirituality" is related to well-being (Sloan and Bagiella 2001, 2002; Thoresen 1999, 2002). Some have seriously criticized applying the notion of spirituality to health-related issues, claiming that "spirituality" largely ignores psychology and reduces existential philosophy to questions of "spiritual" well-being (Salander 2015, 24).

One important problem when studying the role of religion, spirituality, and existential issues in health is that many studies in this field have neglected non-religious populations. In recent years, however, interest has been directed toward secular society and how secular individuals face various crises (Ahmadi 2006, 2015; Ahmadi and Ahmadi 2013; La Cour and Hvidit 2010; Moylan et al. 2015).

Research into religious and spiritual coping has not thoroughly examined patients who are uninterested in institutional religiosity, but follow their own individual paths of spirituality, or those who express no interest at all in spirituality and religiosity. As a step toward looking more closely at this group, an international project was initiated. The purpose of this project has been to carry out international studies on meaning-making coping (i.e., existential, spiritual, and religious coping) among people who have been affected by cancer in a number of secular societies and, thereby, to try to understand the influence of culture on use of these coping methods.

The reason for focusing on South Korea is that a considerable proportion of Koreans do not identify themselves as religious, at the same time as spirituality (what some researchers call "secular spirituality") seems to be strong among the population. As Reed (2007, 5-6) mentions, "Using the Standard Measures of Secularization, we find that the societies of East Asia are highly secularized.... We asked, 'Do you believe in an unseen spiritual world that can influence events in the world we see around us?'” According to Reed (2007), around half of East Asian respondents answered in the affirmative, as high as 70 percent in Taiwan. ${ }^{1}$

The specific goal of the present Korean study was to investigate which of these meaning-making methods-methods that have mostly been ignored in previous studies in the field of religious and spiritual coping - are used by cancer patients in Korea and to determine whether new meaning-making methods could be identified, the more general aim being to develop our theory of the importance of culture in coping.

\section{Literature Review}

\section{Definition of Religion and Spirituality}

In the present project, the definition of religion and spirituality suggested by Ahmadi (2006, 72) is applied:

Religiousness is a search for significance that unfolds within a traditional sacred context. It is then related to an organized system of belief and practice relating to a sacred source that includes individual and institutional expressions, serves a variety of purposes, and may play potentially helpful and/or harmful roles in people's lives.

\footnotetext{
${ }^{1}$ China $49.3 \%$, S. Korea $50.6 \%$, Japan $51.5 \%$, Hong Kong $56.9 \%$, Taiwan $72.3 \%$ (The figures reflect the highest percentages responding to either "Definitely" or "Somewhat." Source: 2005 and 2006 Asia Barometer Surveys).
} 
This definition confines the search for significance to the framework of a traditional sacred context, as does Zinnbauer's definition (Zinnbauer and Pargament 2005, 35-36), and reflects the spirit of our time, which takes exception to traditional authority and institutional expressions of belief. Ahmadi's definition, in contrast to Pargament's (Zinnbauer et al. 1999, 909), enables communication with the general public through its sensitivity to how people self-identify in cultural settings where spirituality is more dominant than religiosity.

Spirituality is more difficult to define than religiosity, because it obviously cannot be so concretely explained. Nevertheless, a working definition was needed to conduct the present study. Ahmadi (2006, 71-72) defines spirituality as follows:

A search for connectedness with a sacred source that is related or not related to God or any religious holy sources. Spirituality involves efforts to consider metaphysical or transcendent aspects of everyday life as they relate to forces, transcendent and otherwise. Hence, spirituality encompasses religion as well as many beliefs and practices from outside the normally defined religious sphere (Jenkins and Pargament 1995, 52-53).

The above definition is based partly on Ahmadi's work and partly on Jenkins and Pargament's (1995, 52-53) definition. Additionally, the construct of spirituality in the present study is in accordance with the definition of Puchalski et al. (2009) defining spirituality as "that aspect of humanity which refers to the way individuals seek and express meaning and purpose and the way they experience their connectedness to the moment, to self, to others, to nature, and to the significant or sacred" (Moylan et al. 2015, 222).

Proceeding from this definition, the term spirituality, as it is used in the present project, refers to the kind of spirituality that can be experienced without having any faith, without myths, legends, and founding super-personalities, without superstition, and that can be practiced in a religious context as well as outside the religious sphere. For people who are socialized in a secular and rationally organized society where people are considered irreligious, it may be difficult to accept as truth many aspects of conventional religions, such as the mythology and legends of super-personalities and superstition. We therefore chose a definition that focuses on spirituality that is experienced in a religious context as well as outside the religious sphere. It should be mentioned that, in our study in Korea, we proceeded from the results of studies conducted in Sweden among people who had been struck by cancer (Ahmadi 2006, 2015). The Swedish studies reveal the occurrence of coping strategies that can hardly be regarded as religious or as spiritual in a religious sense, such as strategies connected to nature. Though not using coping terms, Salander (2015, 13-25) looks at this issue from a more psychological perspective when he tries to understand how people deal with an existential predicament. These kinds of coping strategies can be defined as existential coping strategies, referring to people's search for meaning without any connection whatsoever to religion or religious symbols.

\section{Meaning-Making Coping}

Coping can be defined as a process through which individuals attempt to understand and deal with important demands in their lives (Ganzevoort 1998, 260) or as the search for meaning in times of stress (Pargament 1997, 90). Coping is seen as a multilayered contextual phenomenon that involves a number of basic skills (Lazarus and Folkman 1984, 148; Pargament 1997, 89). Coping involves a meeting between the individual and the 
situation; it is multidimensional, multilayered, and contextual. It involves opportunities and choices and is diverse. Another dimension of coping is that it is a process that develops and changes over time (Pargament 1997, 89).

In previous studies, the terms "religious" and "spiritual" have been used to address coping methods that are essentially based on existential issues (Ahmadi 2006, 2015). Nevertheless, the results of these studies, which were conducted in Sweden among people who had been struck by cancer (Ahmadi 2006, 2015), reveal the occurrence of other coping strategies that can hardly be regarded as religious or spiritual, for instance strategies connected to nature. These kinds of coping strategies can be defined as existential coping strategies, referring to a search for meaning that has no connection whatsoever to religion or religious symbols. The results of the qualitative study conducted by Ahmadi (2006) showed clearly that certain coping methods could not be categorized as religious coping or as spiritual coping. These methods were called "new spiritually oriented coping methods dissimilar to religious coping" (Ahmadi 2006) and included: Spiritual Connection with Oneself, Spiritual Sanctification of Nature, Positive Solitude, Empathy/Altruism, Search for Meaning, Visualization, Healing Therapy, Spiritual Music and Meditation. When analyzing these methods, it was clear that they had much more to do with connectedness to nature, to self, and to others than to something transcendent (God or any spiritual power).

The weakness of the previous analyses on Swedish data is that they were not responsive enough to what the participants were actually saying, thus falling into the same trap other researchers, such as Pargament, were accused of falling into (Ahmadi 2006, 58-71). Although the participants described how they coped with their crisis using methods thatalthough touching upon existential questions - had nothing to do with religion or spirituality, their coping methods were interpreted as a kind of spiritual coping-merely one that was more secular. Contact was also lost with the study's own definition, which maintained that spirituality was "a search for connectedness with a sacred source that is related or not related to God or any religious holy sources" (Ahmadi 2006, 72).

As mentioned, none of the methods employed by participants in the previous study (Ahmadi 2006) had an obvious connection to a sacred source; still these methods were interpreted as being connected to a sacred source and were thus influenced by Pargament's Sanctification theory (Pargament and Mahoney 2005, 192). The term existential coping could have been used, as these methods concern individuals' endeavors to find a sourcein nature, in themselves or in others-that could help them cope with their problems. Their problems have caused an existential vacuum that requires elaboration of the old order into a new order-a new order that could help them fill this vacuum.

What the previous study (Ahmadi 2006) neglected was to realize that Pargament was trying to keep spirituality — as well as any other endeavors in people's existential search for meaning or understanding of the life situation-within the light of religiosity and transcendentally. With the results in hand, and with the clarity of hindsight, it would have been more appropriate to employ secular theories such as attribution theory (Fölsterling 2001). Salander $(2015,39)$ touches upon this issue when explaining Frankl's (1959) perspective on meaning, where meaning is not of "divine" but of cognitive origin. According to this perspective, if individuals are to avoid falling into meaninglessness, they should find some kind of contrasting rational (meaning) as an essential part of restructuring their "worldview." These new experiences are assimilated, and life becomes more comprehensible, predictable, and thus more trustful.

In more secular terms, the process of giving a special meaning to objects may well be encompassed by Winnicott's (1971) intermediate area as well as attribution theory (Fölsterling 2001). According to Winnicott and object relations theory, people are, from 
early childhood to death, able to "play with reality" (Salander 2012, 39). The intermediate area is the mental area of human creation: in childhood in the doll's house or sandbox and in adulthood in the area of art and culture. It is the mental space between the internal world and external reality, and it is thus both subjective and objective. Being human is being in between and thus being able to elaborate with facts, especially when confronted with unexpected negative facts such as a cancer disease.

That is why Ahmadi (2015) concludes that use of the term "meaning-making coping" could prevent misunderstandings of the nature of the non-religious coping methods discussed here. Meaning-making coping is thus used in the present study to address the whole spectrum of religious, spiritual, and existential coping methods.

\section{Culture, Religion, and Coping}

One important issue when discussing religious coping is that we should consider the situations in which religion and coping are woven together. As it seems, religion is more accessible to individuals for whom religion is a major part of their orientation system. An orientation system refers to the way in which culture influences an individual's life. This being the case, it is convenient to maintain that the reason people turn to religion in times of crisis is that it is more accessible in their sociocultural context than are other resources. Religion need not be the only available resource in the individual's orientation system; other sources of help may be easier to access. If this is true, then religion can assume an even greater role as a coping resource for those with limited options. In cultures with large non-religious resources and where religion is less a part of individuals' everyday life, it has a minor role to play in the coping process. To "turn to religion in coping" is primarily a question of religion's position in the culture in which the individual has been socialized. Once religion becomes a larger and more integral part of the orientation system, it occupies an important role in coping. When it is less prominent in the orientation system, and less relevant to life experiences, it loses its importance for coping (Ahmadi 2006; Ellison 1991; Ferraro and Koch 1994; Kesselring et al. 1986; Neighbors et al. 1983; Wicks 1990).

Religion's place as well as the availability of non-religious resources in Sweden and some European and Asian countries differs from the situation in the USA. For example, Sweden, China, South Korea, and Japan seem to be more spiritually than religiously oriented. Thus, it is interesting to see what differences this implies for individuals' selection of meaning-making coping methods. In other words, if we accept that the cultural and social characteristics of a society fundamentally determine the role of religion and spirituality in coping, we should wonder why people turn to religion or chose religiousoriented spirituality or non-religious spirituality, in the face of a crisis in societies where religion does not play an important role in individuals' everyday life.

Concerning the qualitative study discussed above (Ahmadi 2006), the main finding was the discovery of new coping methods, such as Sanctification of Nature, Spiritual Connection with Oneself, Positive Solitude, Altruism, Spiritual Music. The results of a later but related quantitative study (Ahmadi 2015) among people struck by cancer in Sweden showed that religious coping methods received the lowest rankings with regard to use. This indicates clearly that religious coping methods are not highly prevalent among cancer patients in Sweden. When it comes to "spiritual" coping methods, the ranking indicates that some spiritual coping methods are ranked between 9th and 15th place, while others ranked very low (21st-23rd place). This shows that, in Sweden, the prevalence of "spiritual" coping methods is very moderate among people who are struck by cancer. The most prevalent coping methods, as the study clearly shows, are the existential ones. These 
methods were ranked from 1st to 6th place. Thus, the results of the previous quantitative study (Ahmadi 2015) show that strategies related to nature constitute the most important coping method among cancer patients in Sweden.

\section{Methods}

Interview questions for the study in Korea were mainly constructed on the basis of the results from the Swedish study (Ahmadi 2015). Some questions and phrases were modified to be made more suitable to the Korean culture. For example, the English term "God" is either translated into "Hanunim" in Korean for Christians or "Shin" for those who are not Christian, but believe in the existence of the supernatural power.

For the present qualitative study, we chose a convenience sample. A total of 33 participants were recruited in Seoul and its suburban areas. Medical social workers at the oncology center at Severance Hospital of Yonsei University and Samsung Seoul Hospital and a senior nurse at the cancer ward at Kyung Hee University Medical Center informed their patients about the study. Some patients agreed to participate in this study. These patients were those who had survived cancer or those still undergoing chemotherapy. Upon receiving the contact information, the interviewers made a phone call to each participant and set the interview schedule. Participants were also recruited through the interviewers' acquaintances and contacted in the same manner.

\section{Procedure}

Before each interview began, the participants read and signed an informed consent form explaining the purpose of the study and ensuring confidentiality. Each interview was audiorecorded after obtaining the participant's approval. Face-to-face interviews were conducted either at the participants' home or at another preferred location; they lasted from 50 to $120 \mathrm{~min}$, and a semi-structured questionnaire was used. The interviews were conducted from May 2014 through January 2015, and transcriptions were completed by the end of January 2015.

A total of 33 participants completed the interviews. The participants included both males and females, age 20 or older. The number of males and females was approximately equivalent as shown in Table 1. Except for three participants who were in their 20s and 30s, about half were middle-aged adults and the other half older adults. About half of the participants were highly educated and more than half were found to be financially stable. Most participants were living with their spouse and had children. Participants' stage of cancer varied from earliest to severe, and their social status was also diverse, including housewives, a student, retirees, and the currently employed. They self-identified as either non-religious, spiritual or religious (Protestant, Catholic, and Buddhist - the three largest religious groups in Korea). Eleven people reported having no religion, but this does not mean they distanced themselves from spiritual or existential coping.

The first step in analyzing the interview transcripts involved coding, thematizing, and creating networks of different themes. Codes were condensed into categories, and tentative coding schemes were developed first to test their validity. The research team discussed each category of themes and finalized the coding scheme after adding, excluding, and integrating categories. Cultural aspects of the coping strategies of Korean participants were discussed by the research group to complete the data analysis. 
Table 1 Demographic characteristics of the participants $(N=33)$
${ }^{\mathrm{a}}$ Low $=$ less than 2000; midlow $=2000$-less than 4000; midhigh $=4000$-less than 6000 ; high $=6000$ or higher (in US dollars)

\begin{tabular}{|c|c|c|}
\hline Characteristics & $N$ & $\%$ \\
\hline \multicolumn{3}{|l|}{ Gender } \\
\hline Male & 17 & 51.5 \\
\hline Female & 16 & 48.5 \\
\hline \multicolumn{3}{|l|}{ Age } \\
\hline $20-39$ & 3 & 9.0 \\
\hline $40-59$ & 15 & 45.5 \\
\hline $60+$ & 15 & 45.5 \\
\hline \multicolumn{3}{|l|}{ Education } \\
\hline High school graduate or less & 17 & 51.5 \\
\hline College graduate or higher & 16 & 48.5 \\
\hline \multicolumn{3}{|l|}{ Children } \\
\hline Yes & 29 & 87.9 \\
\hline No & 4 & 12.1 \\
\hline \multicolumn{3}{|l|}{ Monthly household income ${ }^{a}$} \\
\hline Mid-low or less & 14 & 42.4 \\
\hline Mid-high or higher & 19 & 57.6 \\
\hline \multicolumn{3}{|l|}{ Stage of cancer } \\
\hline Early to 1 st & 13 & 39.4 \\
\hline 2 nd-3rd & 13 & 39.4 \\
\hline 4th or worse & 7 & 21.2 \\
\hline \multicolumn{3}{|l|}{ Employment status } \\
\hline Working & 15 & 45.5 \\
\hline Retired/on leave & 10 & 30.3 \\
\hline Housewife & 7 & 21.2 \\
\hline Student & 1 & 3.0 \\
\hline \multicolumn{3}{|l|}{ Religion } \\
\hline Buddhist & 5 & 15.2 \\
\hline Catholic & 6 & 18.2 \\
\hline Protestant & 11 & 33.3 \\
\hline No religion & 11 & 33.3 \\
\hline
\end{tabular}

The study was approved by the Uppsala Ethical Vetting Board (equivalent to an institutional review board) in Sweden. To ensure reliability and validity, we strove to meet the four evaluative criteria developed by Lincoln and Guba (1985): credibility, transferability, dependability, and confirmability. First, in order to establish credibility, it was important to develop a rapport with the participants. To achieve credibility, a contextual story was first shared by the interviewers, the aim being to make participants feel comfortable about openly sharing their experiences. After the interviews were completed, the validity of the accounts was confirmed by communicating with the participants via phone or emails regarding their responses to some of the open-ended questions. Second, to establish transferability, the interviews were thorough and lasted until every item in the semi-structured questionnaire had been covered. Third, to establish dependability, the authors discussed their respective findings together at every step of the process to achieve consistency and establish inter-subjectivity. Moreover, to further increase consistency, 
experts on coping with cancer were commissioned to evaluate the findings. Finally, to establish confirmability, the authors considered and discussed their own biases and stereotypes to minimize their influence and maintain their objectivity.

\section{Results}

The 33 participants of present study shared 33 different life stories with the interviewers. Nevertheless, a thematic analysis revealed four major themes of meaning-making coping that are penetrating all the participants: (1) belief in the healing power of nature; (2) mindbody connection; (3) relying on transcendent power; and (4) finding oneself in relationships with others. Each theme is further described in the following (Table 2).

\section{Belief in the Healing Power of Nature}

When asked about their most effective coping resource, some participants mentioned nature as their coping method. While suffering from cancer, participants believed that being close to nature would heal and console their mind and body. Such a belief in the healing power of nature can be divided into two themes: mountains as a healer and the healing power of natural foods.

\section{Mountains as a Healer}

Participants seemed to strongly believe in the healing power of mountains. After being diagnosed with cancer, they tried to stay closer to a mountain because they believed it contained a healing energy that could revitalize all living things. One 58-year-old man who had survived pancreatic cancer explained how much he appreciated having the benefits of the mountain and pine trees.

I went to Gayang Mountain every weekend after completing chemotherapy. I believe Gayang Mountain saved my life. Although I was weak physically, I tried to go there and walk slowly. My wife and I rested under the pine trees, listened to the radio and ate the food we brought. We stayed there for about $5 \sim 6$ h every single day. I liked to be there around $2 \mathrm{pm}$ when the scent of pine tree resin was the strongest. I think pine trees have the power to heal cancer. Gayang Mountain contains great amounts of anion because it borders the west sea. Anion is very good for cancer patients.

Table 2 Overview of results by themes and sub-themes

\begin{tabular}{|c|c|}
\hline Themes & Sub-themes \\
\hline \multirow[t]{2}{*}{ Belief in the healing power of nature } & Mountains as a healer \\
\hline & The healing power of natural foods \\
\hline \multirow[t]{2}{*}{ Mind-body connection } & Peaceful mental attitude \\
\hline & Positive life perspective \\
\hline Relying on transcendent power & - \\
\hline Finding oneself in relationships with others & - \\
\hline
\end{tabular}


The participants not only believed that a mountain had cured their cancer, but they also found consolation from just being on it. One 65-year-old woman who had survived the severe stage of colorectal cancer showed her affection for a mountain.

I believe the mountain helped me in healing my cancer. I keep climbing the mountain even now. I love the fresh air, doing exercise, listening to music and hearing the latest news from the other women there. My eyes are not good after I got cancer, so I rely on the mountain and sometimes try to see it through the window in my room.

\section{The Healing Power of Natural Foods}

Concerning the healing power of nature as an effective coping resource, almost all of the participants mentioned natural foods. They believed that these foods worked as an anticancer medicine. Among various kinds of foods, the fast-fermented yellow bean paste (called Chung-Gook-Chang in Korean) was the most frequently mentioned. Another 65-year-old woman believed that Chung-Gook-Chang had cured her cancer.

I ate the powder of dried Chung-Gook-Chang, about 10 kilograms every year. I was unable to eat rice because I had diabetes. So I have had Chung-Gook-Chang at 10 a.m. and 2 p.m. every day for 6 years, with vegetables. I believe that this powder is responsible for my survival. I don't eat meat or flour, but I eat greens and yellow bean paste most of the time.

One 56-year-old woman believed that colorful vegetables had an anticancer effect on breast cancer. She expressed this as follows:

I eat all kinds of foods. People say purple vegetables are good for breast cancer, so I try to eat eggplant. I also eat colorful paprika, blueberries, cabbages white and purple, and broccoli. I love to eat vegetables.

There are numerous mountains in Seoul and its suburban areas. Korean people are fond of being in nature and enjoy going to the mountains in their leisure time (Ministry of Culture, Sports, and Tourism 2013). Popular books and television programs in Korea have depicted how people cured their disease by living in the mountains or eating healthy natural foods produced. Participants had already experienced or heard about the benefits of mountains and specific natural foods for curing cancer. They thought it was important to follow the advice of their physicians completely, but also believed in the healing power of nature. Some participants believed that human life originated from nature and must return to it when the human body and mind malfunction.

\section{Mind-Body Connection}

When we asked whether they had ever thought about why they got cancer, participants stated that the stress of a busy lifestyle and uneasy mental state had caused the cancer. They believed that a negative and complex mental state could cause the body to dysfunction. This can be interpreted as belief in a body-mind connection. Several participants mentioned the term "Ah-dung-bah-dung" in Korean, which means they did their utmost to survive and achieve material success. They regretted their "Ah-dung-bah-dung" lifestyle after being struck by cancer and realized that a peaceful mental attitude was helpful in overcoming a life crisis. While struggling with cancer, participants tried to maintain a balance between mind and body, and to remain in a positive state of mind. We found two 
patterns of coping related to the mind-body connection: the first one we called "peaceful mental attitude" and the second "positive life perspective."

\section{Peaceful Mental Attitude}

The suspicion that cancer might have been caused by stress and a negative mental state caused participants to pay attention to their mental attitudes. Participants often stated that they tried to empty their mind of or push away everything they were obsessed with, whether these obsessions concerned their work or their relationships. Going through the psychological problems caused by cancer and thinking about the possibility of death made concerns about life issues and relationships meaningless for them. They believed that too much thinking about ethical and moral codes had made them stressed and caused their cancer. They began to be less concerned about these issues. The most important task after being struck by cancer was, as they explained, to try to attain peace of mind. One 46-yearold woman who had joined a peer-counseling group after finishing her chemotherapy explained that she had learned how to let out her emotions and live with a peaceful mind. She clarified this as follows:

I changed a lot after I survived cancer. I thought I got stomach cancer because of severe stress from my work, so I thought I have to change myself in order to survive. I learned how to let out ugly words and insults. Before my cancer, I did not let things out but tried to look like a good person.... In the past, I thought I could do anything with my own strength. Now I realize that I can't do anything on my own. I was locked in the frame that I had made. Through cancer, I broke the frame and became free.

Likewise, one 63-year-old man broke the frame of ethical and moral codes after being struck by cancer and, as he put it, "made himself free." He said:

I suppressed my emotions and adjusted my behaviors according to a frame that I had made. I tried not to cause stress in others or not to behave harshly toward them. I always behaved like other people expected me to. I restrained too much. I only cared about what others thought about me. Now I don't care about what they think. I just do whatever I like. I put everything away. I let it out.

\section{Positive Life Perspective}

Surprisingly, some participants appreciated having had or currently having cancer. The reason was that, as they stressed, the painful journey they had undergone made them feel more grateful in their present life and brought about "a turning point" in their life-a new life and new attitudes. While struggling with cancer, participants used the positive-lifeperspective coping method, either by interpreting the situation from a positive perspective or by strengthening their feeling of self-responsibility. One 42-year-old man explained how much he had changed after struggling with cancer. He added that having a positive mindset had helped him survive stomach cancer for 6 years after his surgery in 2009.

I came to appreciate small ordinary things after cancer. The most pleasant thing is that I wake up and read the newspaper in the morning. That may sound trivial, but I am grateful just to open my eyes in the morning and realize I'm alive. When I read the newspaper, I see what is going on in the world. I open the window and have a cup of tea while sitting on the couch. When I listen to music, I feel so happy and grateful. 
People's greed is endless. Since I think this life is a bonus, a second new life, I appreciate even small things. I'm grateful to be alive.

One 65-year-old woman thought the cause of cancer was mental stress. In order to be free of stress, she tried to maintain a positive state of mind.

When I feel bad, I try to relax myself or leave the situation that might disrupt my peace of mind. I would like to live with a new mindset. I don't want to scowl at others. It's not good for me either. I always try to live with a positive state of mind.

Participants showed a high level of resilience in facing their cancer. They tended to think that their survival depended on how they coped with cancer. Rather than blaming the external environment, they tried to find their own solutions by taking responsibility for their actions. One 63-year-old man showed considerable self-responsibility in dealing with his cancer.

You can get as much as you try for. Nothing is for free. A miracle is something you expect to get for free, without any charge. I don't think anything in life is free of charge. The more you give, the more you get. Give and Take. You should make your effort first and then you will cure your cancer.

Korean people have a saying: "Do your best, then God will do the rest," which originated from the History of Three States in China. A self-responsible attitude toward cancer reflects this idea among participants, namely that you should first do your best and then let God (or the universe) do the rest in curing your cancer. Korean participants showed high levels of selfresponsibility, which led to an active approach to coping with cancer. A high level of selfresponsibility also reflects Confucianism, which has affected the mindset of people in South Korea. Taking responsibility for one's own life is strongly emphasized in Confucianism.

\section{Relying on Transcendent Power}

Regardless of whether participants were religious, they had prayed to God on their way to surgery. Regardless of how they defined a supreme power-the Lord, Buddha, their deceased parents, or the universe-they needed an omnipotent being to rely on. Cancer surgeries do not necessarily lead to death, but participants felt a fear of death and worried about the family members who would be left behind. Religious people had their own coping methods in concert with their religiosity, and those who were not religious were also consoled by some coping methods, such as spiritual meditation. This is reflected in the following citations:

Prayer and meditation were the most helpful healing resource for me. When I have severe pains, I talk to God. Whom can I talk to? Mother? Daughter? Doctor? I just rely on God. That is the only thing I can do (53-year-old Protestant woman).

I prayed to the Almighty to find relief in my heart. When people are desperate, they hope and pray. I wanted to believe and hope. I knew praying itself would not bring me what I wished. But I just wanted to do it because I was desperate. I just wanted to have hope. (43-year-old non-religious man).

I feel very relieved when I visit a Buddhist temple. When I feel I'm suffocating in my heart, I just keep murmuring Gwan-se-um-bo-sal (the Goddess of Mercy in Buddhism). I pray to Gwan-se-um-bo-sal asking Her to help me empty my mind (56year-old Buddhist woman). 


\section{Finding Oneself in Relationships with Others}

When asked about the most helpful coping resource for cancer, several participants mentioned "the people around me." Feelings of loneliness are not uncommon when people are struggling with cancer. The participants explained that when they were dealing with cancer, they came to realize they were not alone. They found themselves surrounded by close friends, neighbors or other patients in the hospital who had given their sincere support. It was consoling for participants to know that people were caring and praying for them.

More than 25 million people live in the city of Seoul and its suburban areas. In such a crowded society, Koreans tend to be guarded and wary of social interaction. Prior to diagnosis, participants guarded themselves against other people so as not to be hurt by them. However, after experiencing cancer, participants came to realize that they were loved by the people around them and that they did not need to be wary of human relationships. Feelings of gratitude for the unconditional care they had received caused them to reflect on their life and their relationships with others. Participants wanted to get along with people rather than stay alone at home. Awareness of their relationships with others helped participants cope with cancer, as in the quote below.

One 45-year-old woman expressed this as follows:

Because I feel that anything could happen to me, I regretted having fought with my son and my husband. Why did I do my utmost to succeed, why didn't I love them more? I would like to be generous and love people with all my heart.

One 58-year-old man said in this respect:

When people visited me and said 'You have lived an attractive life. You will overcome. You will win.' These words gave me great strength. People's encouragement was of great help. I realized I had a life that was recognized by others. Then I felt relieved.

Alfred Adler, the Austrian psychologist, has earned great admiration in Korea during recent years. He emphasizes that human beings can grow and transition from self-interest to social interest. After enduring the hardships of cancer, participants developed from having a sense of self-interest to an awareness of social relationships and social interests, as Adler suggests. Rather than remaining in solitude as an individual, Korean participants preferred getting along with others.

\section{Discussion}

The goal of the present study was to explore the coping resources that Korean people with cancer found most helpful and to investigate the impact of culture on choice of coping methods. We found four different coping resources among Korean people with cancer: (1) belief in the healing power of nature; (2) mind-body connection; (3) relying on transcendent power; and (4) finding oneself in relationships with others. Although experiences of cancer differed for each participant, one meaning derived from these experiences that participants had in common can be described as "a turning point in life." Struggling with cancer was a great ordeal for each individual, but the struggle did not end only as an ordeal. Experiences with cancer gave participants an opportunity to appreciate the small things in 
daily life, to feel free from worrying about what others think, to regret having fought with others about nothing, and to find themselves in relationships with beloved others.

Just as in the previous study with Swedish participants (Ahmadi 2015), the Korean participants also found relief in the healing power of nature. Korean people tend to understand the universe and their living environments based on the theory of Yin-Yang and Five Elements. The theory of Yin-Yang and Five Elements (pronounced "um-yang-ohheng-sol") has been shared for thousands of years among people in the Asian countries, including Korea and China. Yin and Yang indicate two opposite forces, such as cold and hot, dark and light, and moon and sun. Five Elements refers to the energies found in wood, fire, earth, metal, and water, which are intertwined with Yin and Yang in everything.

The reason participants in the present study believed in the healing power of mountains and natural foods is probably because they understand the mechanisms of nature as being based on the theory of Yin-Yang and Five Elements. Koreans share the oriental philosophy that human beings are part of nature and will return to nature, which is the root of all living things (Jean 1998). The natural foods that were believed to help participants heal their cancer were produced from the earth. Participants found relief and vitality while visiting the mountains or eating healthy foods and believed strongly that their mind and body would be healed in the arms of nature.

Participants in the present study had a clear belief that life stress caused by their "ahdung-bah-dung" lifestyle had led to cancer. As it seems, such a belief among Korean people with cancer is a result of their conviction that living with a negative mental state has a negative impact on the body.

Although Mind-Body Medicine and the psychosomatic approach ${ }^{2}$ have been popular in Western countries, the perspective and practices of the mind-body connection have a long history in Korea. Similar to "Zen," which is well known in the West, Kuk-Sun-Do is a traditional practice in Korea and is used to enrich the mind, body, and soul in nature. KukSun-Do had been used as a mind-body-soul training program for political leaders and scholars for thousands of years. However, it deteriorated in the Chosun Dynasty, which lasted until the early twentieth century when other religions (especially Christianity) were introduced from the West. Not every Korean practices Kuk-Sun-Do today, but the mindbody connection perspective has its root in the principles and practices of Kuk-Sun-Do.

Cancer is at the top of the ranking of primary causes of death in Korea (Statistics Korea 2013). Korean people may be afraid and anxious about being diagnosed with cancer and associate cancer with the possibility of their own death. As participants explained, when they were diagnosed with cancer for the first time, they experienced a state of blackout for a while. The blackout state of mind can be compared to being trapped in a dark cave. The first thing available to them in this desperate situation was to rely on a transcendent or omnipotent power, which could be Jesus Christ, Buddha, the Virgin Mary or another supreme being. Regardless of whether they were religious, Korean participants described having felt relieved when they prayed to a transcendent power.

Some researchers believe that religiosity or spirituality has a positive impact on subjective well-being among cancer patients (Koenig 1995; Pargament 1997; Schreiber and Edward 2015), while others question the actual importance and effectiveness of such an

\footnotetext{
${ }^{2}$ Mind-Body Medicine started in the 1960s at Harvard University, where the program was led by Dr. Herbert Benson's research team. Benson examined the connection between high blood pressure and stress and found that emotional relief and relaxation, instead of medical treatment, helped cure disease. Since then, complementary medicine has been developed for various types of diseases, including cancer, and psychosomatic therapies based on the mind-body connection have been found to be effective among cancer patients (Carlson et al. 2004; Grossman et al. 2004; Ledesma and Kumano 2009).
} 
impact (Poole and Higgo 2010; Powell et al. 2003; Sloan 2006; Sloan et al. 2001). Ahmadi (2015) found that existential meaning-making coping methods, especially nature and a sense of self-control, were the most meaningful coping strategies among cancer patients in Sweden. South Korea is not a religious country. According to Gallup Korea (2015), around $50 \%$ of people in South Korea adhere to some religion (Buddhism $22 \%$, Protestant $21 \%$, and Catholic $7 \%$ ); however, many are spiritual and incorporate elements of Shamanism into their daily living. For example, there are people who often visit fortune tellers or shamans when they have to make a critical decision (e.g., concerning a wedding, job), attach wish ribbons to old trees in the village, stack wishing stones in the mountains, or believe that the ghost of the deceased comes to visit during a memorial service. Whether or not Korean people are aware of it, their behaviors do reveal a high level of spirituality. Therefore, it is not surprising that people with cancer, as the participants explained, desperately rely on a transcendent power regardless of their level of religiosity.

Finally, Korean participants reported that realizing people would take care of them and help them cope with their illness was a positive aspect of having cancer, because it made them think about what they could do to help others. The cancer patients in Sweden expressed gratitude for those who helped them during their illness, but what helped many was the coping method "positive solitude." Positive solitude helped them find themselves and the strength to handle the psychological effects of their illness; it allowed them to be alone and think about their life, especially about existential issues (Ahmadi 2006, 2015).

On the contrary, Korean participants became conscious of themselves in their relationships with others and preferred to get along with others while they were struggling with cancer. In many studies, social support or social relationships are found to have a positive impact on quality of life among Koreans, especially those struggling with cancer (Han and Lee 2011; Kim et al. 2008; Lee et al. 2014). In Korea, the population of the city of Seoul and its suburban Gyonggi area is more than 22 million. About 20 percent of the Korean population lives in Seoul, and thus the city is overcrowded. Moreover, South Korea is thought to have the highest speed Internet services in the world. Thus, it would seem that Korean society is interconnected thanks to its advanced technology. However, Koreans may experience ambivalence in such a crowded and interconnected society. They may experience "solitude in the crowd," as the American sociologist David Riesman stated in his book Lonely Crowd (Riesman et al. 2001). It is possible that Korean people feel even lonelier while struggling with cancer, because people who have never experienced cancer may find it difficult to empathize with others who are on "the day-to-day cancer journey" (Wilkes et al. 2003, 414). Therefore, people with cancer may appreciate it when, unexpectedly, others come to take care of them and offer unconditional support to help them overcome their disease.

Having learned about the meaning-making coping among Korean participants with cancer, limitations of this study should be mentioned. First, most of the participants were aged 40 and older and only three participants were in their $20 \mathrm{~s}$ or $30 \mathrm{~s}$. The meaningmaking coping may present different themes among younger people compared to those who are older. Second, almost all kinds of cancer were included in this study although some types of cancer such as thyroid cancer were relatively easy to cure. Moreover, participants with all stages of cancer were included in this study. Depending on the type or the stage of cancer, participants may have different experiences of meaning-making coping.

Despite limitations, the present study shows the importance of different existential coping methods; it indicates that when existential questions come into the picture in coping, even non-religious coping methods should be seriously taken into consideration. 
Moreover, the study shows clearly the impact of culture on choice of coping methods. Thus, it is important to investigate the cultural context when we explore coping resources and meaning-making experiences among cancer patients. Future researchers are encouraged to design a longitudinal study to investigate the changing patterns of coping and meaning-making among cancer survivors living in different countries.

\section{References}

Ahmadi, F. (2006). Culture, religion and spirituality in coping: The example of cancer patients in Sweden. Uppsala: Uppsala University.

Ahmadi, F. (Ed.). (2015). Coping with cancer in Sweden: A search for meaning. Uppsala: Uppsala University.

Ahmadi, F., \& Ahmadi, N. (2013). Nature as the most important coping strategy among cancer patients: A Swedish survey. Journal of Religion and Health, 52(4), 1177-1190.

Carlson, L. E., Speca, M., Patel, K. D., \& Goodey, E. (2004). Mindfulness-based stress reduction in relation to quality of life, mood, symptoms of stress and levels of cortisol, dehydroepiandrosterone sulfate (DHEAS) and melatonin in breast and prostate cancer outpatients. Psychoneuroendocrinology, 29(4), 448-474.

Cobb, M., Puchalski, C. M., \& Rumbold, B. (2012). Oxford textbook of spirituality in healthcare. Oxford: Oxford University Press.

Ellison, C. G. (1991). Religious involvement and subjective well-being. Journal of Health and Social Behavior, 32(1), 80-99.

Ferraro, K. F., \& Koch, J. R. (1994). Religion and health among black and white adults: Examining social support and consolation. Journal for the Scientific Study of Religion, 33(4), 362-375.

Fölsterling, F. (2001). Attribution: An introduction to theory, research and application. Philadelphia: Psychology Press.

Frankl, V. (1959). Man's search for meaning. Boston: Bacon Press.

Ganzevoort, R. R. (1998). Religious coping reconsidered, part two: A narrative reformulation. Journal of Psychology and Theology, 26(3), 276-286.

Grossman, P., Niermann, L., Schmidt, S., \& Walach, H. (2004). Mindfulness-based stress reduction and health benefits: A meta-analysis. Psychosomatic Research, 57(1), 35-43.

Han, I., \& Lee, I. (2011). Study on the factors that affect the posttraumatic growth of cancer patients. Social Welfare Research, 42(2), 419-441.

Jean, G. H. (1998). Environmental ethics: Natural preservation and respect to life in the East and the West. Seoul: Minum Publisher.

Jenkins, R. A., \& Pargament, K. I. (1995). Religion and spirituality as sources for coping with cancer. Journal of Psychosocial Ontology, 13(1-2), 51-74.

Kesselring, A., Dodd, M. J., Lindsey, A. M., \& Strauss, A. L. (1986). Attitude of patients living in Switzerland about cancer and its treatment. Cancer Nursing, 9(2), 77-85.

Kim, H., Kwon, J., Kim, J., Lee, L., \& Lee, K. (2008). Exploring the factors of posttraumatic growth among breast cancer survivors. The Korean Journal of Health Psychology, 13(3), 781-799.

Koenig, H. G. (1995). Research on religion and aging. New York: Greenwood Press.

Koenig, H. G., King, D. E., \& Carson, V. B. (2012). Handbook of religion and health. New York: Oxford University Press.

Korea, Gallup. (2015). The religion of Koreans 1984-2014. Seoul: Gallup Korea Research Institute.

La Cour, P., \& Hvidit, N. C. (2010). Research on meaning-making and health in secular society: Secular, spiritual and religious existential orientations. Social Science Medicine, 71(7), 1292-1299.

Lazarus, S. R., \& Folkman, S. (1984). Stress, appraisal, and coping. New York: Springer.

Ledesma, D., \& Kumano, H. (2009). Mindfulness-based stress reduction and cancer: A meta-analysis. Psycho-Oncology, 18(6), 571-579.

Lee, M., Yoo, Y., \& Hwang, E. (2014). Experiences of self-help group activities among breast cancer patients. Korean Journal of Adult Nursing, 26(4), 466-478.

Lincoln, Y., \& Guba, E. (1985). Naturalistic inquiry. Newbury Park: Sage.

Ministry of Culture, Sports, and Tourism. (2013). A white paper on leisure. Seoul: Krihongbo.

Moylan, M. M., Carey, L. B., Blackburn, R., Hayes, R., \& Robinson, P. (2015). The Men's Shed: Providing biopsychosocial and spiritual support. Journal of Religion and Health, 54(1), 221-234. 
Neighbors, H. W., Jackson, J. S., Bowman, P. J., \& Gurin, G. (1983). Stress: Coping, and Black mental health: Preliminary findings from a national study. Prevention in Human Services, 2(3), 5-29.

Padela, A. I., \& Curlin, F. A. (2012). Religion and disparities: Considering the influences of Islam on the health of American Muslims. Journal of Religion and Health, 52(4), 1333-1345.

Pargament, K. I. (1997). The psychology of religion and coping. New York: Guilford Press.

Pargament, K. I., \& Mahoney, A. (2005). Sacred matters: Sanctification as a vital topic for the psychology of religion. The International Journal for the Psychology of Religion, 15(3), 179-198.

Phelps, A. C., Maciejewski, P. K., Nilsson, M., Balboni, T. A., Wright, A. A., Paulk, M. E., et al. (2009). Religious coping and use of intensive life-prolonging care near death in patients with advanced cancer. The Journal of the American Medical Association, 301(11), 1140-1147.

Poole, R., \& Higgo, R. (2010). Psychiatry, religion and spirituality: A way forward. The Psychiatrist, 34(10), 452-453.

Powell, L. H., Shahabi, L., \& Thoresen, C. E. (2003). Religion and spirituality: Linkages to physical health. American Psychologist, 58(1), 36-52.

Puchalski, C., Ferrell, B., Virani, R., Otis-Green, S., Baird, P., Bull, J., et al. (2009). Improving the quality of spiritual care as a dimension of palliative care: The report of the Consensus Conference. Journal of Palliative Medicine, 12(10), 885-904. doi:10.1089/jpm.2009.0142.

Reed, S. R. (2007). Analyzing secularization and religiosity in Asia. Japanese Journal of Political Science, $8(3), 327-339$.

Riesman, D., Glazer, N., \& Denney, R. (2001). The lonely crowd: A study of the changing American character. New Heaven: Yale University Press.

Salander, P. (2012). Cancer and "playing" with reality: Clinical guidance with the help of the intermediate area and disavowal. Acta Oncologica, 51(4), 541-560.

Salander, P. (2015). Introduction: A critical discussion on the concept of spirituality in research on health. In F. Ahmadi (Ed.), Coping with cancer in Sweden: A search for meaning (pp. 13-27). Uppsala: Uppsala University.

Schreiber, J. A., \& Edward, J. (2015). Image of God, religion, spirituality, and life changes in breast cancer survivors: A qualitative approach. Journal of Religion and Health, 54(2), 612-622.

Sloan, R. P. (2006). Blind faith: The unholy alliance of religion and medicine. New York: St Martin's Press.

Sloan, R. P., \& Bagiella, E. (2001). Spirituality and medical practice: A look at the evidence. American Family Physician, 63(1), 33-35.

Sloan, R. P., \& Bagiella, E. (2002). Claims about religious involvement and health outcomes. Annals Behavioral Medicine, 24(1), 14-21.

Sloan, R. P., Bagiella, E., \& Powell, T. (2001). Without a prayer: Methodological problems, ethical challenges, and misrepresentations in the study of religion, spirituality, and medicine. In T. G. Plante \& A. C. Sherman (Eds.), Faith and health: Psychological perspectives (pp. 339-354). New York: Guilford Press.

Statistics Korea. (2013). Statistics on the causes of death in year 2013. Seoul: Statistics Korea.

Tarakeshwar, N., Vanderwerker, L. C., Paulk, E., Pearce, M. J., Kasl, S. V., \& Prigerson, H. G. (2006). Religious coping is associated with the quality of life of patients with advanced cancer. Journal of Palliative Medicine, 9(3), 646-657.

Thoresen, C. E. (1999). Spirituality and health, is there a relationship? Journal of Health Psychology, 4(3), 291-300.

Thoresen, C. E. (2002). Spirituality and health: What's the evidence and what's needed? Annals of Behavioral Medicine, 24(1), 3-13.

Wicks, J. W. (1990). Greater Toledo area survey. Bowling Green, OH: Population and Society Research Center.

Wilkes, L. M., O’Baugh, J., Luke, S., \& George, A. (2003). Positive attitude in cancer: Patients' perspectives. Oncology Nursing Forum, 30(3), 412-416.

Winnicott, D. (1971). Playing and reality. London: Tavistock Publications.

Zinnbauer, B. J., \& Pargament, K. I. (2005). Religiousness and spirituality. In R. F. Paloutzian \& C. L. Parks (Eds.), Handbook of psychology and religion (pp. 21-42). New York: The Guilford Press.

Zinnbauer, B. J., Pargament, K. I., \& Scott, A. B. (1999). The emerging meaning of religiousness and spirituality: Problems and prospects. Journal for Personality, 67(6), 889-919. 